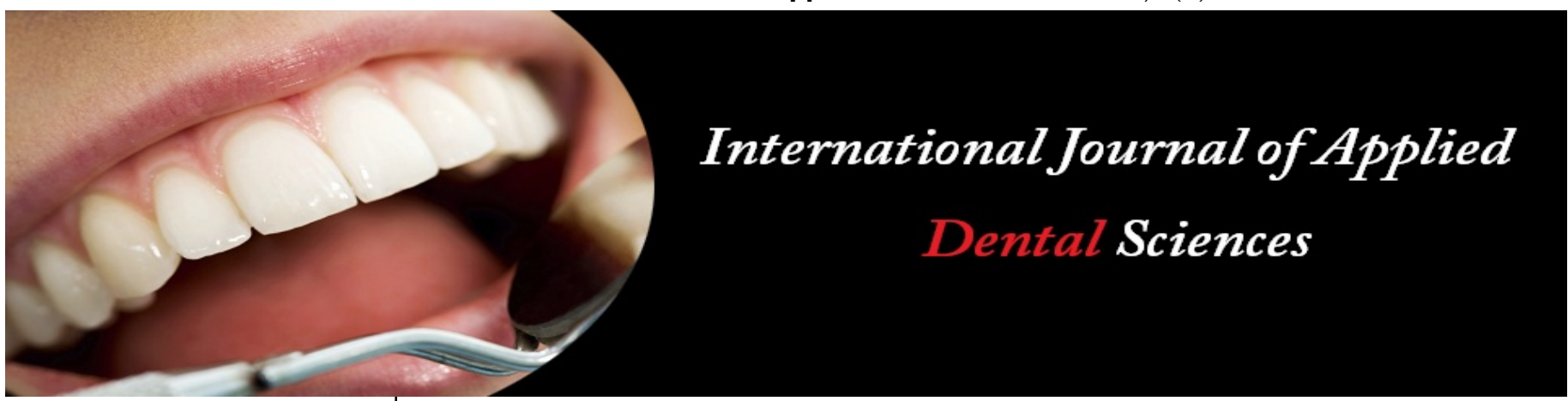

ISSN Print: 2394-7489

IJADS 2021; 7(3): 374-379

(C) 2021 IJADS

www.oraljournal.com

Received: 07-05-2021

Accepted: 09-06-2021

Dr. Bhavana Sajeevan Nair Final Year Post-Graduate, Vokkaligara Sangha Dental College and Hospital, Bangalore,

Karnataka, India

Dr. Surendra Kumar GP

Head, Department of

Prosthodontics, Vokkaligara

Sangha Dental College and

Hospital, Bangalore, Karnataka,

India

Dr. Arjun Mithra

Sr lecturer, Department of

Prosthodontics, Vokkaligara

Sangha Dental College and

Hospital, Bangalore, Karnataka, India

\section{Savitha Rao}

Sr lecturer, Department of

Prosthodontics, Vokkaligara

Sangha Dental College and

Hospital, Bangalore, Karnataka,

India

Dr. Tanuja Murthy

Sr lecturer, Department of

Prosthodontics, Vokkaligara

Sangha Dental College and

Hospital, Bangalore, Karnataka,

India
ISSN Online: $2394-7497$

\section{To evaluate and compare the mechanical properties and wetting ability of heat polymerized polymethyl methacrylate resin after reinforcement with halloysite nanotubes and Titania nanoparticles}

\author{
Dr. Bhavana Sajeevan Nair, Dr. Surendra Kumar GP, Dr. Arjun Mithra, \\ Savitha Rao and Dr. Tanuja Murthy
}

DOI: https://doi.org/10.22271/oral.2021.v7.i3f.1324

\section{Abstract}

To evaluate and compare the mechanical properties and wetting ability of heat polymerized polymethyl methacrylate resin after reinforcement with halloysite nanotubes and titania nanoparticles. A conventional heat-cured resin (DPI heat cure material) will be used as the matrix component while halloysite (group A) and titania (group B) nanoparticles as a reinforcing agent. Group C specimens will be fabricated with trevalon (Trevalon - HI). The specimens will be stored in distilled water overnight to simulate oral environment before performing the tests for determining the flexural strength (FS) and contact angle (CA). The contact angle data states that Halloysite reinforced PMMA is more hydrophilic. UTM analysis states that Flexure strength of trevalon highest amongst all the three group. Resin reinforced with halloysite had higher contact angle hysteresis hence greater retentive value and wetting ability while travelon had higher flexure strength.

Keywords: halloysite nanotubes, titanium nanoparticle, Trevalon, flexure strength, contact angle

\section{Introduction}

The numerous advantages of polymethyl methacrylate (PMMA) make it the most dominant polymer used as denture base material. The ease of processing, low cost, light weight, stability in the oral cavity and aesthetic properties are few advantages of this material. However, it has poor surface properties and weak mechanical properties including impact and flexural strengths. Therefore, to accomplish the expected outcome, resins should be reinforced using different materials to enhance their properties.

In this study two variants of nanoparticles namely, halloysite nanotube (HNT) and Titania/Titanium dioxide nanoparticles (TiO2NP) will be reinforced into PMMA to produce hybrid resins. The diameters of HNTs are approximately in tens of nanometers, length 200 $\mathrm{nm}$ to $1-2 \mu \mathrm{m}$. Hence it can be easily processed and can be dispersed uniformly into the resin matrix. The literature investigated the effect of TiO2NP on some properties of PMMA but a comprehensive study on the overall performance of PMMA nanocomposite was not observed. Properties of TiO2NP has proved to have antimicrobial properties. Moreover, both the materials are cost effective, biocompatible, chemically stable, free of toxicity, resistant to corrosion with high strength. Therefore, this study aims to investigate the effect of incorporation of HNTs and TiO2NP into PMMA resin there after evaluating the wetting ability and mechanical property in terms of flexural strength, young's modulus of the hybrid resin

\section{Materials and Method}

\section{Sample_grouping:}

Dr. Surendra Kumar GP Head, Department of Prosthodontics, Vokkaligara Sangha Dental College and Hospital, Bangalore, Karnataka, India
The study was carried out on 24 specimens (PMMA blocks). The specimens were categorized into 3 groups $(n=8)$ coded A to C. Group $C$ was the control group (unmodified high strength acrylic resin specimens) fabricated using trevalon (Trevalon - HI). The specimens of the remaining two groups (A and B) was modified with addition of halloysite nanotubes and titania nanoparticles respectively. 
Group A: PMMA (DPI heat cure material) reinforced with halloysite nanotubes. Group B: PMMA (DPI heat cure material) reinforced with titania nano particles. Group C: Trevalon (Trevalon - HI)

\section{Sample preparation}

Modelling wax patterns sized $65 \mathrm{~mm} \times 10 \mathrm{~mm} \times 10 \mathrm{~mm}$ (figure 1a) were prepared using silicon moulds. The patterns were invested (figure 1b) and later on dewaxed to obtain plaster moulds (figure 2) of the desired size. The acrylic specimens were then prepared by packing the unmodified and modified acrylic resin into the moulds present in denture flasks.
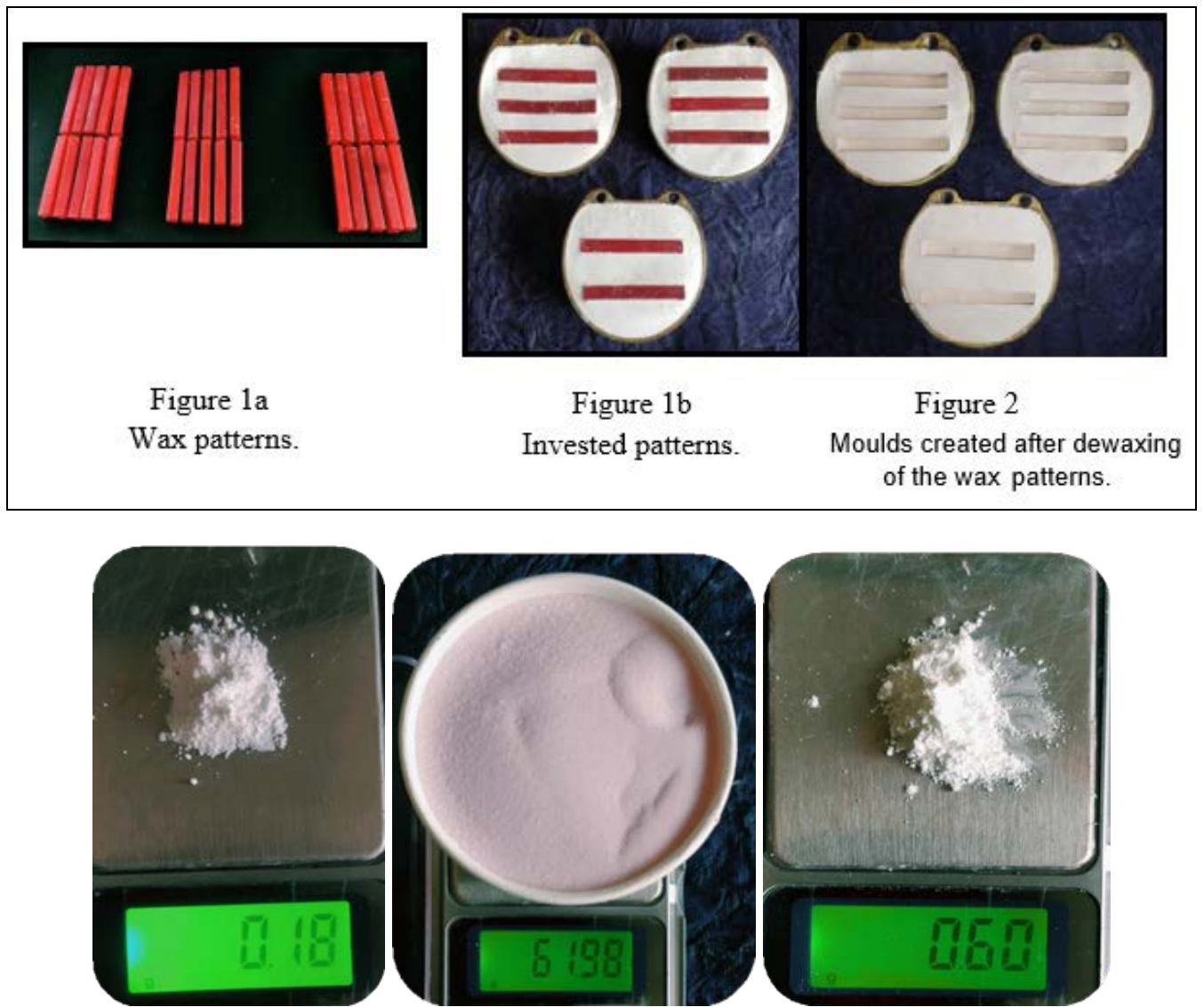

Fig 3: (a) Halloysite nanotubes 0.3 wt\%. 60gms of PMMA (weight of the container 1.98gms.) Titania nanoparticles 1 wt $\%$.

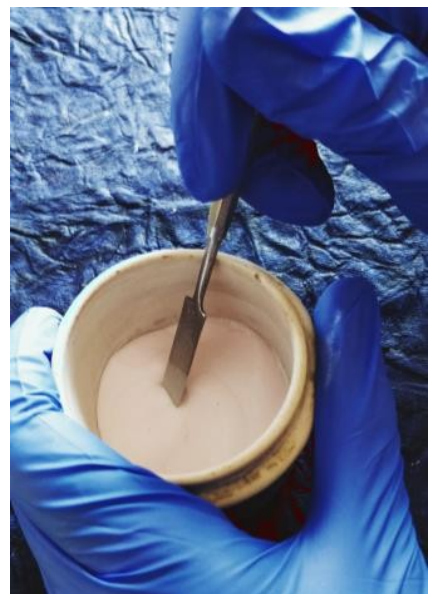

Fig 4: Nanoparticles being reinforced into PMMA by hand mixing.

For preparation of group A and B specimens, conventional heat-cured resin was used as matrix component, HNTs and TIO2 nanoparticles as the reinforcing agent. The nanoparticles and PMMA was thoroughly mixed using a mortar and pestle for initial mixing and blending, followed by hand tumbling in a porcelain jar (figure 3 and 4) until an even colour was obtained. The resin powder was then mixed with monomer in a ratio of 2:1 by volume in a mixing jar with a tightly fitting lid.
The specimens were stored in normal water for a week to simulate oral environment before performing tests for determination of the flexural strength (FS) and contact angle (CA). The flexural strength was measured using a three- point bending test in a universal testing machine at a crosshead speed of $5 \mathrm{~mm} / \mathrm{min}$. Specimens were loaded until fracture occurred. From the stress-strain curve, the flexural strength and Young's modulus was calculated.

Wetting ability or the contact angle of the resin blocks will be assessed by evaluation of the contact angle hysteresis obtained by calculating the advancing and receding angle made by a drop of distilled water on the surface of the specimen.

\section{Flexure strength measurement}

Specimens were tested by 3-point bend test on Lloyd universal testing machine (Model multitest 10, Mecmesin, CENSE) at a cross head speed of $5 \mathrm{~mm} / \mathrm{min}$

For the 3-point bend test, a fixture was fabricated as shown in figure 5. The maximum force $(\mathrm{F})$ necessary to produce fracture of the specimen was recorded in Newton $(\mathrm{N})$. The flexural strength $\mathrm{Q}$ was calculated in (MPa) for all specimens using Equation.

where "F" is the maximum/fracture force in Newton (N), "I" is the distance between the two supporting points in (mm); " $\mathrm{B}$ " is the specimen width in (mm) and " $\mathrm{H}$ " is the specimen height subjected to bending in ( $\mathrm{mm})$. 


\section{$\mathrm{Q}=\frac{3 \mathrm{FI}}{2 \mathrm{BH}^{2}}$}

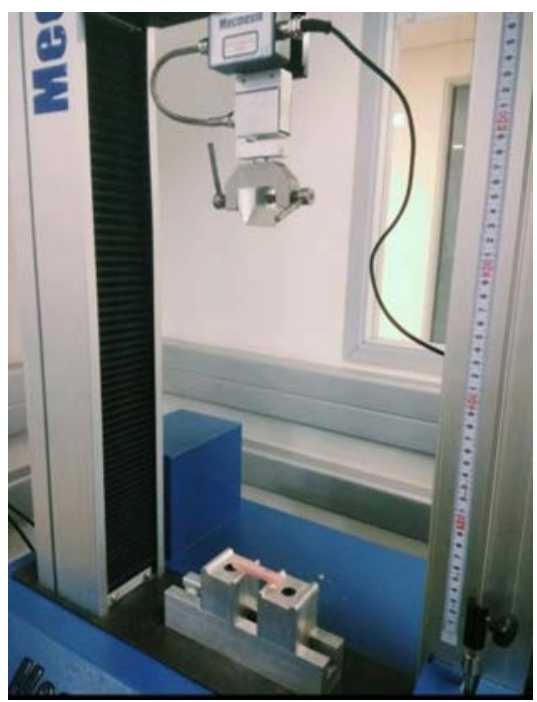

Fig 5: Utm analysis

\section{Contact angle}

Dynamic contact angle analysis was carried out to measure the advancing and receding contact angles made by the liquid on the specimes.

The fluid/media, in this study- distilled water, to be tested was dispensed by a syringe onto the specimen (Figure 6).

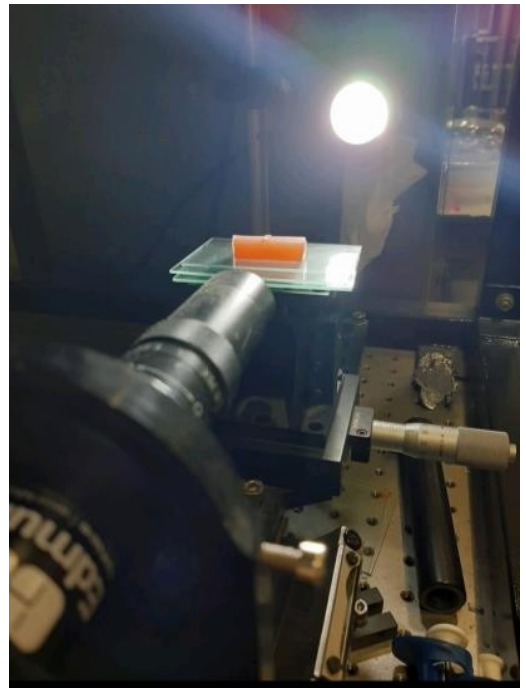

Fig 6: contact angle analysis.

The system allows for a standardized volume of fluid to be used on the specimen surface while measuring the advancing and receding contact angles. The system uses a high-speed camera to record changes of the drop contour which has been dispensed on to the specimen surface. The system's program determines the advancing and receding contact angles. (figure 7 and 8)

The advancing contact angles for the liquid used in this study were generally independent of time in the range of 1 to 10 minutes. Readings, therefore, were made 1 to 2 minutes after placement of the drop on the surface.

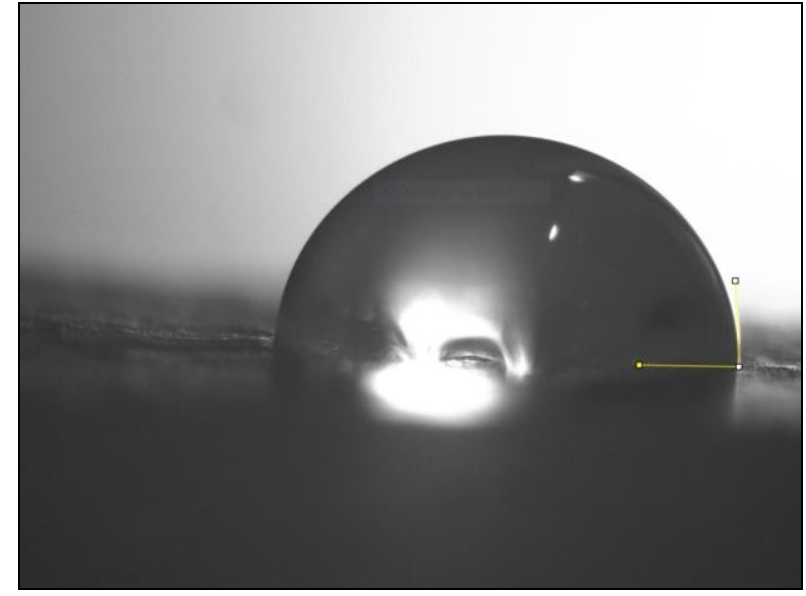

Fig 7: Advancing contact angle being recorded on group A (halloysite) specimen.

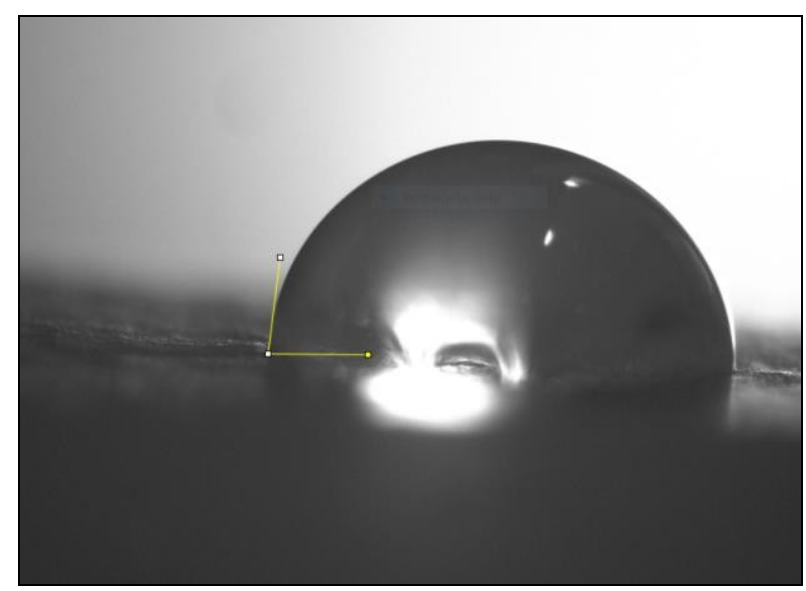

Fig 8: Receding contact angle being recorded on group A (halloysite) specimen.

\section{Discussion}

A common and inevitable problem faced while using acrylic denture base is its fracture. Therefore, various trials were done to bring about an improvement in the mechanical properties of PMMA. It can be achieved in the following three ways:

1. Replacing PMMA with an alternative material.

2. Chemically modifying it.

3. Reinforcing the PMMA with other materials like fibres or metals ${ }^{[24,25]}$.

This investigation principally aimed to assess possible changes in the mechanical properties (the flexural strength and contact angle) of two types of PMMA namely high impact acrylic resin (trevalon) and conventional PMMA modified by infusion of two types of nanoparticles (TiO2 nanoparticles and halloysite nanotubes).

In nanotechnology different nano materials are used like carbon nanotubes, nanofluids, nanoparticles, nanoemulsions, nanocapsules. the results of these nano materials are not considered safe for humans and for the environment as well due to their toxic effects. Halloysite nanotubules (HNTs) are naturally occurring environmental friendly nanotubules and are cost effective. HNTs have high mechanical strength and modulus. Due to these properties halloysites are considered ideal for various applications. They are also used in the fabrication of high quality white-ware ceramics. Due to easy dispersability in polymer matrix, abundant availability and biocompatibility, HNTs are also used in different dental 
materials. 12 On the other hand, TiO2 nanoparticles are increasingly used owing to the impressive features as nontoxicity, chemically inactivity, low cost, high refractive index, antibacterial effect, corrosion resistant and high micro hardness. Furthermore, literature has also showed that nanoscale $\mathrm{TiO} 2$ reinforcement agents bring new optical, electrical, physiochemical properties attained at very low $\mathrm{TiO} 2$ content, which makes polymer- $\mathrm{TiO} 2$ nanocomposites a promising new class of materials. It can be anticipated that it will be commercially beneficial for widespread fields ${ }^{[22,23]}$. Moreover, TiO2 nanoparticles have been used as additives to biomaterials in order to induce antimicrobial properties. Antimicrobial activities of $\mathrm{TiO} 2$ against Candida albicans, Staphylococcus aureus, Pseudomonas aeruginosa, Escherichia coli, Lactobacillus acidophilus, etc. have been proved by recent studies ${ }^{[1]}$.

To the best knowledge of the authors, the most suitable concentration for the addition of different nanometals to the acrylic resin that can lead to the best properties is doubtful until now. Addition of nanoparticles beyond a proven threshold makes it behave like a plasticizer thus causing slippage of molecules and compromising the mechanical properties of the resin.

Literature has proved that concentrations above 5\% have led to massive changes in the colour of acrylic which decreases its aesthetic value and patient acceptance ${ }^{[18]}$.

Therefore, the two concentrations: $0.3 \%$ by weight of halloysite nanotube and $1 \%$ by weight of titania nanoparticles were selected $^{[11,20]}$.

Adhesion, defined as the attraction of unlike molecules, is one of the fundamental forces involved in denture retention. The wettability of a liquid to a solid surface plays an important role in determining adhesion ${ }^{[25]}$

The wettability of a liquid to a solid surface can be studied by measuring the contact angles formed between them. However, the fundamental requirement suggested for denture retention is contact angle hysteresis. Contact angle hysteresis (CAH) can be defined as the difference of the advancing $(\mathrm{A})$ and the receding $(\mathrm{R})$ contact angle for a contact line moving in an opposite direction at the same velocity ${ }^{[28]}$.

$\mathrm{CAH}$ is one of the most important and classic elements of wetting of liquid droplets in systems from centimeter to micrometer scales. Higher the contact angle hysteresis, greater is the retention.

It is perhaps most intuitively understood by looking at a droplet resting on a vertical substrate (picture) ${ }^{[27]}$.

The hysteresis of the contact angle ( $\square \mathrm{A}-\square \mathrm{R}$ ) for pure liquids is mainly caused by surface flaws which could be geometric flaws/ surface roughness/the heterogeneous chemical composition of the surface. In case of polymers, the presence of liquid in contact with a solid may provoke the reorientation of surface groups, leading to contact angle hysteresis. In addition, contact angle hysteresis of polymer surfaces can be induced by the mobility and reorientation of surface polymeric chains ${ }^{[16,29]}$.

\section{Result}

Data was subjected to normalcy test (Shapiro-wilk test). Data showed non normal distribution. Hence non-parametric tests (Kruskal-wallis with post hoc Mann-whitney) were applied. Kruskal-wallis test showed statistically significant difference between groups of types of acrylic resin. The group $\mathrm{C}$ (trevalon) showed significantly highest mean flexural strength followed by group B (titania). The lowest flexure strength was seen in group A (halloysite). There were significant differences $(\mathrm{P}<0.05)$ between studied groups.

Flexural strength measured for all specimens groups and values are listed in Table 1:

Table 1: Comparison of Utm Among the Groups Using Kruskal Wallis Test.

\begin{tabular}{|c|c|c|c|c|}
\hline Group & Minimum & Maximum & Median & P value \\
\hline Halloysite & 107.86 & 123.4 & 106.6 & \multirow{2}{*}{$0.001^{*}$} \\
\hline Travelon & 124.11 & 179.2 & 145.6 & \\
\hline Titania & 83.7 & 138.4 & 118.7 & \\
\hline
\end{tabular}

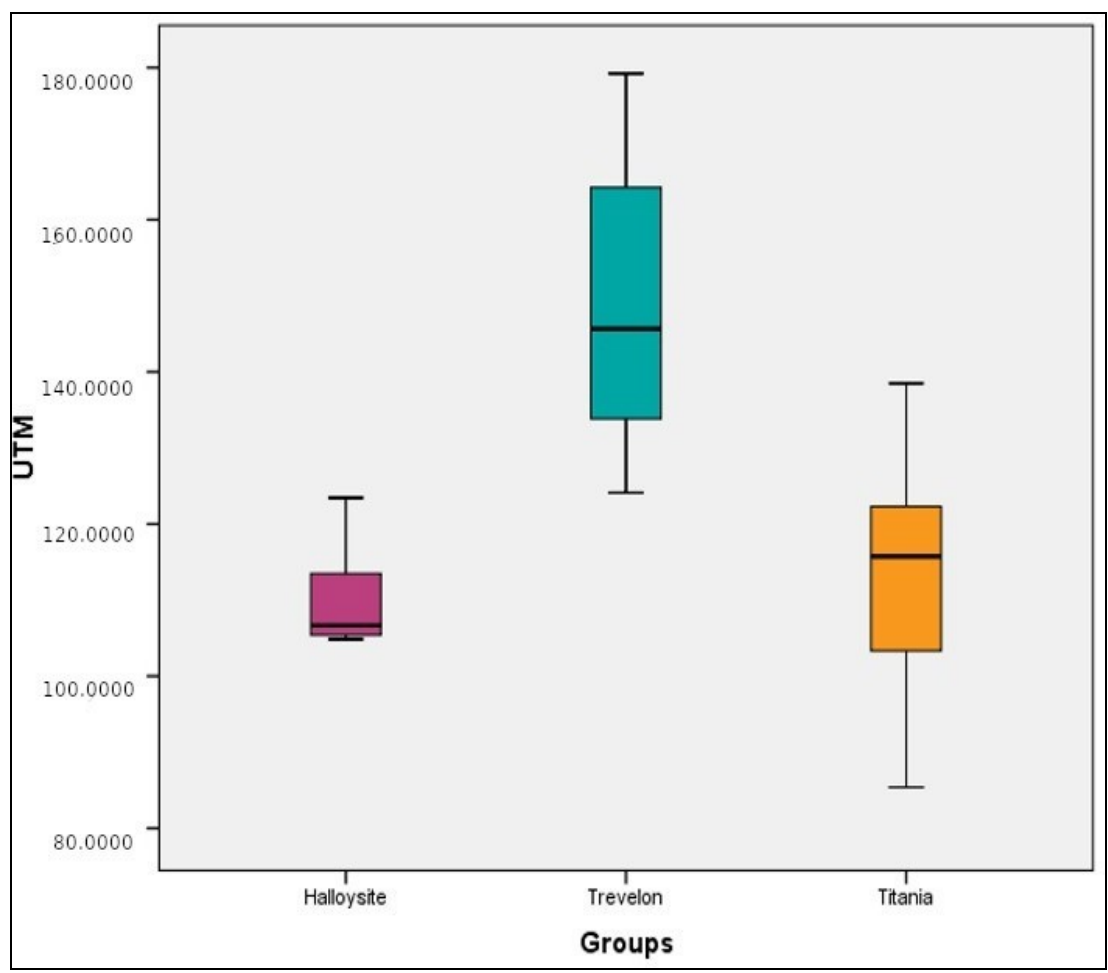




\section{Contact angle}

The data were statistically analyzed using Kruskal-wallis test. The results of the analysis are presented in tables 2 and graphically depicted.

The contact angle data (Table 2) clearly indicate that the heatpolymerized samples reinforced with HNTs are more hydrophilic (CAH- 2.92) than the samples made of trevalon (CAH- 2.83) and reinforced with TIO2 nanoparticles (CAH2.25)

Highest hysteresis values were calculated for group A (halloysite) followed by group C (trevalon). Low-advancing and receding contact angles were demonstrated on group B (titania) denture base material.

Table 1: Comparison of Contact Angle (1a-1b) Among the Groups Using Kruskal Wallis Test.

\begin{tabular}{|c|c|c|c|c|c|}
\hline Group & Minimum & Maximum & Median & IQR & P value \\
\hline Trevalon & 1.31 & 4.99 & 2.83 & 2.67 & \multirow{2}{*}{0.225} \\
\cline { 1 - 5 } Halloysite & 1.77 & 5.69 & 2.92 & 2.2 & \\
\hline Titania & 0.85 & 3.98 & 2.25 & 1.82 & \\
\hline
\end{tabular}

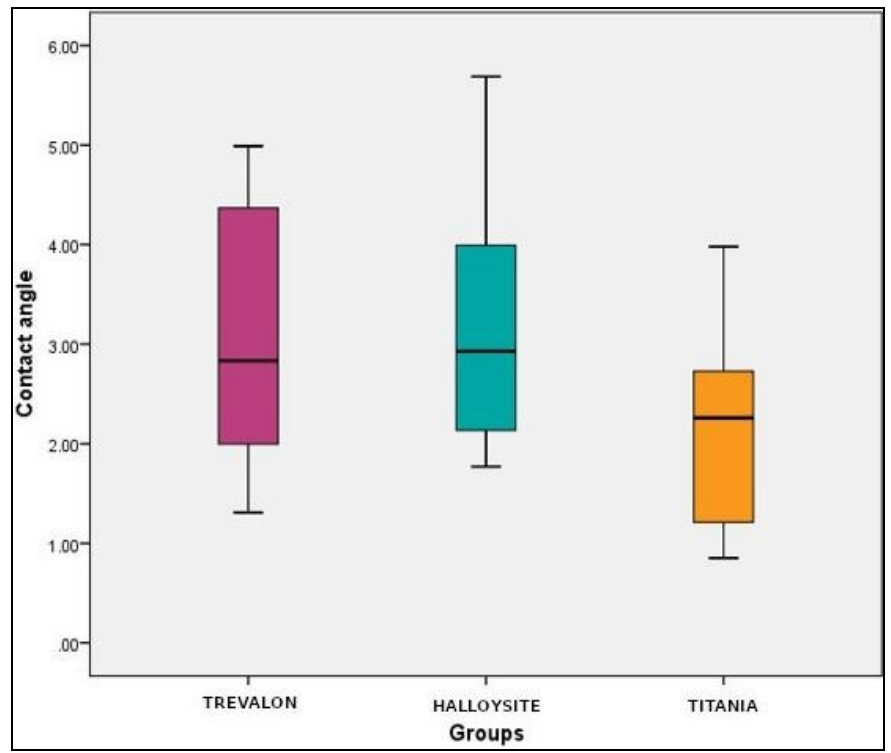

\section{Conclusion}

Within the limitations of this study, it could be concluded that: Flexure strength of group C, trevalon was demonstrated to be the highest amongst all the three groups hence provided better fracture resistance followed by group B (titania) and lastly group A (halloysite)

Group A, halloysite nanotube reinforced PMMA has better wetting ability and could possibly provide the best retention of the three denture base materials tested as it had the highest hysteresis value. This was followed by group C (trevalon) and lastly group B (titania).

\section{References}

1. Ahmed MA, El-Shennawy M, Althomali YM, Omar AA. Effect of titanium dioxide nano particles incorporation on mechanical and physical properties on two different types of acrylic resin denture base. World Journal of Nano Science and Engineering 2016;6(3):111-9.

2. Gad MM, Abualsaud R. Behavior of PMMA denture base materials containing titanium dioxide nanoparticles: A literature review. International journal of biomaterials. 2019.

3. Hardita A, Ismiyati $\mathrm{T}$, Wahyuningtyas E. Effect of addition titanium dioxide nanoparticles as acrylic resin denture base filler on cytotoxicity. Majalah Kedokteran Gigi Indonesia. 5(2):86-91.

4. Sun J, Petersen EJ, Watson SS, Sims CM, Kassman A, Frukhtbeyn $\mathrm{S}$ et al. Biophysical characterization of functionalized titania nanoparticles and their application in dental adhesives. Acta biomaterialia 2017;53:585-97.

5. Bangera MK, Kotian R, Ravishankar N. Effect of titanium dioxide nanoparticle reinforcement on flexural strength of denture base resin: A systematic review and meta-analysis. Japanese Dental Science Review. 2020;56(1):68-76.

6. Karci M, Demir N, Yazman S. Evaluation of flexural strength of different denture base materials reinforced with different nanoparticles. Journal of Prosthodontics. 2019;28(5):572-9.

7. Gad MM, Fouda SM, Al-Harbi FA, Näpänkangas R, Raustia A. PMMA denture base material enhancement: a review of fiber, filler, and nanofiller addition. International journal of nanomedicine 2017;12:3801.

8. Hashem M, Rez MF, Fouad H, Elsarnagawy $T$, Elsharawy MA, Umar A et al. Influence of titanium oxide nanoparticles on the physical and thermomechanical behavior of poly methyl methacrylate (PMMA): a denture base resin. Science of Advanced Materials 2017;9(6):938-44.

9. Alrahlah A, Fouad H, Hashem M, Niazy AA, AlBadah A. Titanium oxide (TiO2)/polymethylmethacrylate (PMMA) denture base nanocomposites: mechanical, viscoelastic and antibacterial behavior. Materials. 2018;11(7):1096.

10. Hamouda IM, Beyari MM. Addition of glass fibers and titanium dioxide nanoparticles to the acrylic resin denture base material: comparative study with the conventional and high impact types. Oral Health Dent Manag. 2014;13(1):107-12.

11. Abdallah RM. Evaluation of polymethyl methacrylate resin mechanical properties with incorporated halloysite nanotubes. The journal of advanced prosthodontics 2016;8(3):167.

12. Fathima B, Dhaded S. Halloysite Nanotubes And Its Applications. Guident 2018;11(8).

13. Li X, Liu W, Sun L, Aifantis KE, Yu B, Fan Y, Feng Q, Cui F, Watari F. Resin composites reinforced by nanoscaled fibers or tubes for dental regeneration. BioMed research international 2014.

14. Holder JA, McNally LM, Barbour ME. Halloysite Nanotubes as Nanofillers to Reinforce Glass Ionomer Cements.

15. Brugnara M, Volpe CD, Siboni S, Zeni D. Contact angle analysis on polymethylmethacrylate and commercial wax by using an environmental scanning electron microscope. Scanning 2006;28(5):267-73.

16. Monse P, Baszkin A, de Lourdes Costa M, Lejoyeux J. Complete denture retention. Part II: Wettability studies on various acrylic resin denture base materials. The Journal of prosthetic dentistry 1989;62(3):308-12.

17. Sipahi C, Anil N, Bayramli E. The effect of acquired salivary pellicle on the surface free energy and wettability of different denture base materials. Journal of dentistry 2001;29(3):197-204.

18. Scolaro C, Torrisi L, Cutroneo M, Caridi F, Roszkowska AM, Pedullà E. A Liquid contact angles on biocompatible surfaces. In3rd Workshop-Plasmi, Sorgenti, Biofisica ed Applicazioni 2013;29:38-42.

19. Kilani BH, Retief DH, Guldag MV, Castleberry DJ, 
Fischer TE. Wettability of selected denture base materials. The Journal of prosthetic dentistry 1984;52(2):288-91.

20. Bangera MK, Kotian R, Ravishankar N. Effect of titanium dioxide nanoparticle reinforcement on flexural strength of denture base resin: A systematic review and meta-analysis. Japanese Dental Science Review 2020;56(1):68-76.

21. Reijnders $\mathrm{L}$. The release of $\mathrm{TiO} 2$ and $\mathrm{SiO} 2$ nanoparticles from nanocomposites. Polymer degradation and stability. 2009;94(5):873-6.

22. Chatterjee A. Properties improvement of PMMA using nano TiO2. Journal of applied polymer science 2010;118(5):2890-7.

23. Kim SH, Watts DC. The Effect of Reinforcement with Woven E-Glass Fibers on the Impact Strength of Complete Dentures Fabricated with High-Impact Acrylic Resin. The Journal of Prosthetic Dentistry 2004;91:274280.

24. Jagger DC, Harrison A, Jandt KD. The Reinforcement of Dentures. Journal of Oral Rehabilitation 1999;26:185194.

25. Basskin A, Ter-Minassian-Saraga L. Effect of temperature on the wettahility of oxydized polyethylene films. Polymer 1974;15:759. 